Research Article

\title{
Design of Frequency- and Pattern-Reconfigurable Wideband Slot Antenna
}

\author{
Liping Han (ㅁ), Caixia Wang, Wenmei Zhang, Runbo Ma, and Qingsheng Zeng \\ College of Physics and Electronics Engineering, Shanxi University, Shanxi 030006, China \\ Correspondence should be addressed to Liping Han; sxdxhlp@126.com
}

Received 25 July 2017; Accepted 28 December 2017; Published 14 February 2018

Academic Editor: Symeon Nikolaou

Copyright (c) 2018 Liping Han et al. This is an open access article distributed under the Creative Commons Attribution License, which permits unrestricted use, distribution, and reproduction in any medium, provided the original work is properly cited.

\begin{abstract}
A wideband slot antenna with frequency- and pattern-reconfigurable characteristics for TD-LTE (3.4-3.8 GHz) and C-band $(3.7-4.2 \mathrm{GHz})$ applications is proposed. The antenna consists of two symmetric slots that are fed by a fork-shaped microstrip line. Two PIN diodes are loaded in the slots to produce two different frequency bands. Meanwhile, two additional PIN diodes are inserted in the feed line to achieve the pattern reconfigurability. The wideband operation is realized by using the symmetric slots and fork-shaped feed line. Simulated and measured results show that the antenna provides $25^{\circ}$ and $20^{\circ}$ beam-steering in 3.4-3.8 and 3.7-4.2 GHz bands, respectively. Also, an impedance bandwidth of at least $12.8 \%$ is obtained in the operating bands.
\end{abstract}

\section{Introduction}

In recent years, reconfigurable antennas have attracted a lot of attention in the modern wireless communication systems. Frequency-reconfigurable antennas allow frequency hopping and dynamic spectrum allocation [1], while patternreconfigurable antennas can filter in-band interference and increase the channel capacity $[2,3]$. A number of reconfigurable antennas have been reported. In [4-6], the antennas can switch between different resonant frequencies by changing the states of the PIN diodes. In [7], a lumped capacitor is inserted in the middle of a slotted patch antenna, and the operation bands can be tuned continuously. In [8], an improved phased array pattern-reconfigurable antenna is proposed. By tuning the capacitive reactance of the varactors, the main beam of the array can scan from $-70^{\circ}$ to $70^{\circ}$ in the $\mathrm{H}$-plane. In [9], pattern reconfigurability is realized by incorporating four PIN diodes and two parasitic elements. In [10], the adjacent pixels are connected by PIN diodes to change the surface current, thus providing reconfigurability in the beamsteering direction.

The aforementioned reconfigurable antennas tune the frequency and radiation pattern individually. However, the manipulation of an antenna's frequency and pattern enables the systems to suppress the spatial noise, avoid electronic jamming, and save energy. Many studies have been conducted on the simultaneous reconfiguration of frequency and pattern. In [11], Huff presents a pattern- and frequency-reconfigurable microstrip antenna using a small number of switches. In [12], a frequency- and patternreconfigurable slot antenna is proposed. In [13], the reconfigurable antenna can switch their operation between a patch broadside pattern and a monopole omnidirectional pattern using PIN diodes. In [14], an aperture-coupled frequencyand pattern-reconfigurable stacked array antenna is presented. In [15], a novel planar parasitic array antenna with reconfigurability in both frequency band and radiation pattern is proposed.

The simultaneous reconfiguration of the frequency and pattern with wideband operation is an interesting and challenging area to be explored. A frequency- and patternreconfigurable wideband slot antenna is proposed in this paper. The antenna consists of two sickle-shaped slots and a fork-shaped feed line. Two switches are placed in the slots to achieve frequency reconfiguration, and two additional PIN diodes are positioned in the feed line to produce pattern reconfiguration. The wideband operation is realized by using the symmetric slots and fork-shaped feed line. The simulated and measured results show that the antenna has the capability to change its patterns in two frequency bands. 


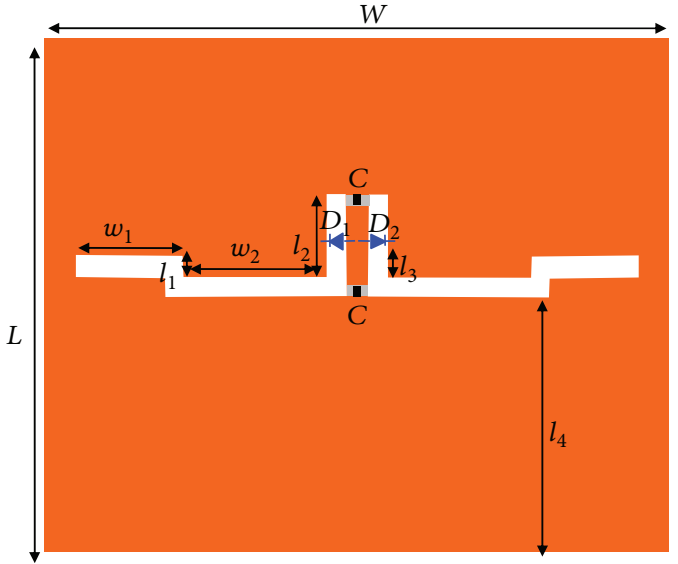

(a)

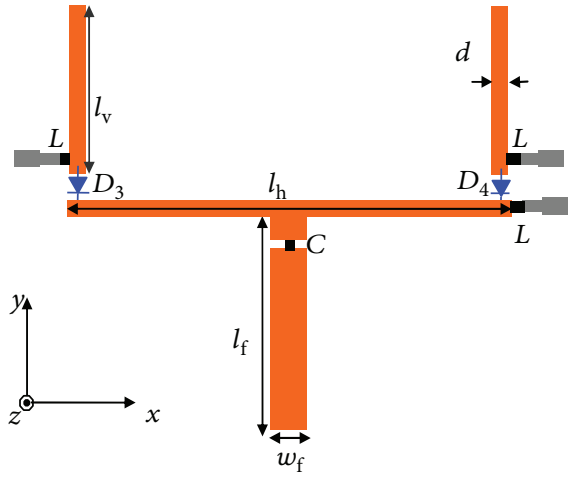

(b)

FIGURE 1: Geometry of antenna. (a) Top view and (b) bottom view (white-radiating slots, light gray-biasing slots, dark gray-biasing strips, and dark block-capacitors and inductors).

TABLE 1: Operation modes of antenna.

\begin{tabular}{lllllc}
\hline Diodes & $\mathrm{D}_{1}$ & $\mathrm{D}_{2}$ & $\mathrm{D}_{3}$ & $\mathrm{D}_{4}$ & Frequency band $(\mathrm{GHz})$ \\
\hline Mode 1 & Off & Off & On & On & $3.25-3.88$ \\
Mode 2 & Off & Off & Off & On & $3.38-3.94$ \\
Mode 3 & Off & Off & On & Off & $3.38-3.94$ \\
Mode 4 & On & On & On & On & $3.69-4.34$ \\
Mode 5 & On & On & Off & On & $3.61-4.2$ \\
Mode 6 & On & On & On & Off & $3.61-4.2$ \\
\hline
\end{tabular}

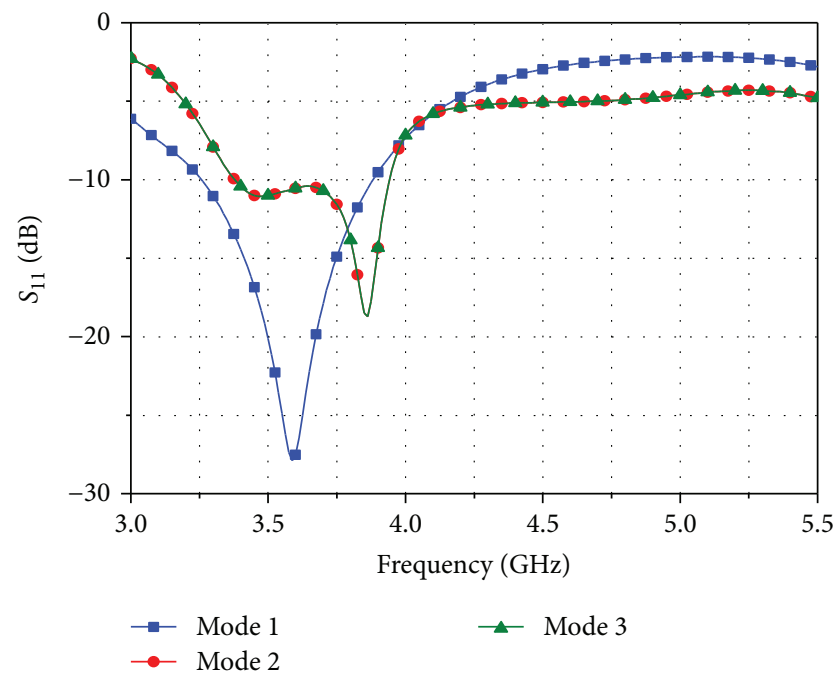

Figure 2: Simulated input reflection coefficients in modes 1, 2, and 3 .

\section{Antenna Design}

2.1. Antenna Geometry. The configuration of the antenna is shown in Figure 1. On one side of the substrate is the ground plane with two sickle-shaped slots and on the other side is the fork-shaped microstrip feed line. Two PIN diodes $\left(D_{1}\right.$ and $\left.D_{2}\right)$ are loaded in the sickle-shaped slots to

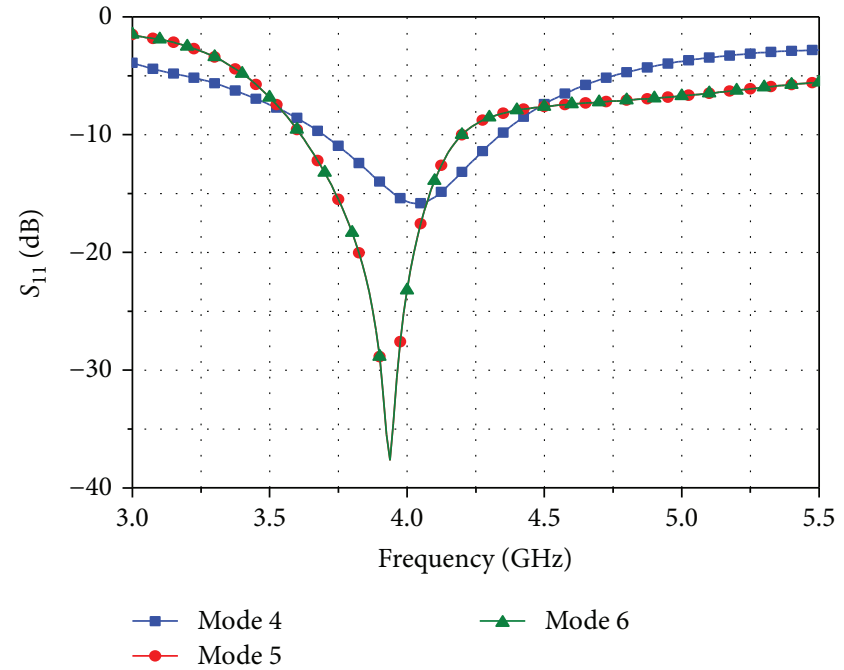

FIGURE 3: Simulated input reflection coefficients in modes 4, 5, and 6 .

realize the frequency reconfigurability, while two additional PIN diodes $\left(D_{3}\right.$ and $\left.D_{4}\right)$ are inserted in the connection between the horizontal and vertical arms of the feed line to achieve the pattern reconfigurability. Furthermore, two small slots with a width of $0.5 \mathrm{~mm}$ are introduced in the ground plane for biasing $\mathrm{D}_{1}$ and $\mathrm{D}_{2}$, and two $10 \mathrm{pF}$ capacitors are mounted across the slots to provide RF wave connection throughout the ground plane. For biasing $\mathrm{D}_{3}$ and $\mathrm{D}_{4}$, three biasing strips are etched beside the feed line, and three $12 \mathrm{nH}$ inductors are joined for isolating the RF signals while maintaining the dc connection. Meanwhile, a $10 \mathrm{pF}$ capacitor is placed in the feed line to prevent the dc current flowing into RF source of the antenna.

The proposed antenna is designed to operate in 3.4-3.8 and 3.7-4.2 GHz bands and simulated with CST Microwave Studio. The chosen substrate is FR4 with a thickness of $1.6 \mathrm{~mm}$ and a relative permittivity of 4.4 . The optimized parameters of the antenna are $L=30 \mathrm{~mm}, W=40 \mathrm{~mm}$, 


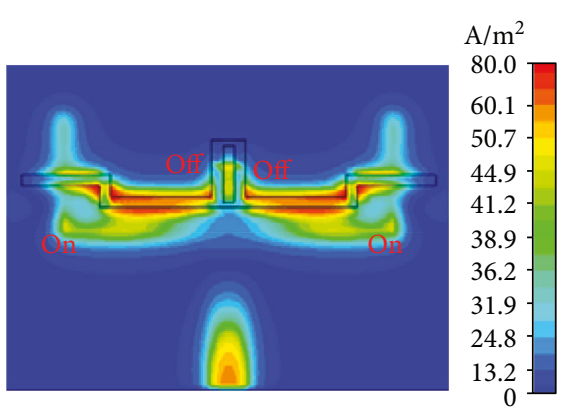

(a)

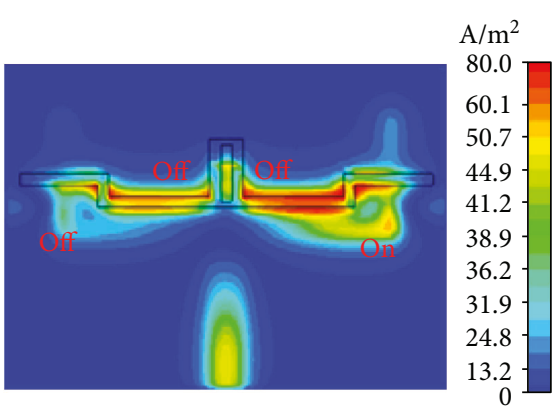

(b)

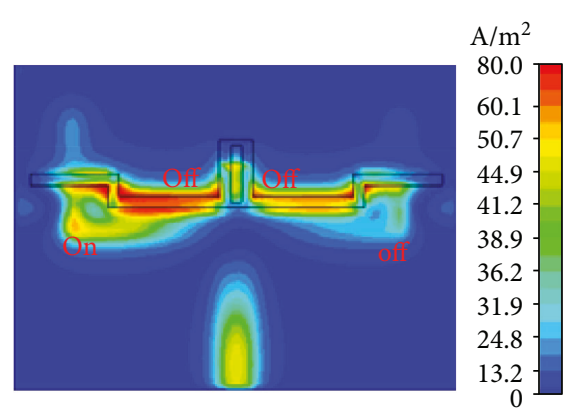

(c)

Figure 4: Surface current distributions. (a) Mode 1. (b) Mode 2. (c) Mode 3.

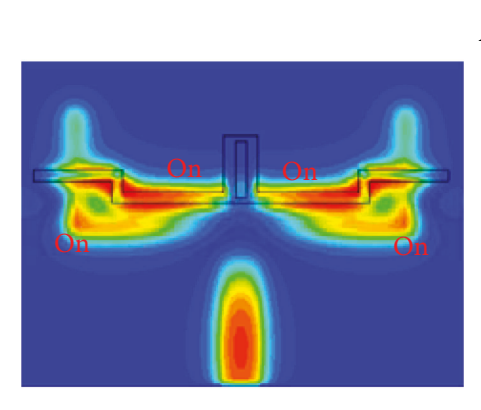

(a)
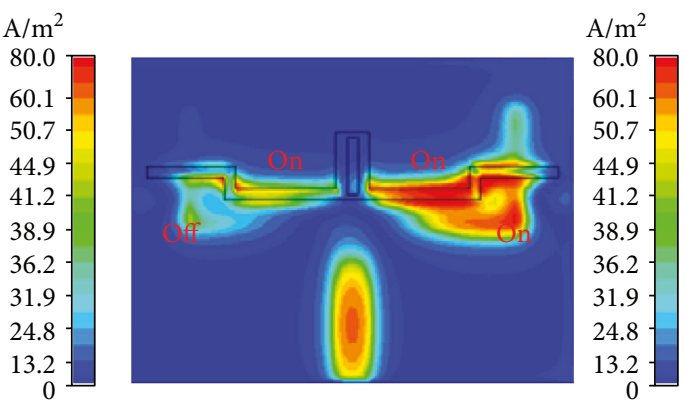

(b)

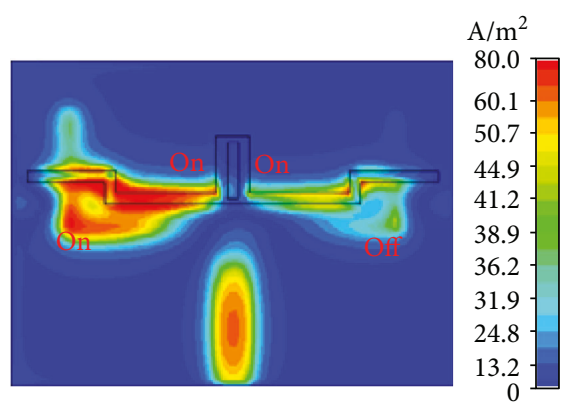

(c)

Figure 5: Surface current distributions. (a) Mode 4. (b) Mode 5. (c) Mode 6.

$w_{1}=6.5 \mathrm{~mm}, w_{2}=9 \mathrm{~mm}, l_{1}=1 \mathrm{~mm}, l_{2}=4 \mathrm{~mm}, l_{3}=1.3 \mathrm{~mm}$, $l_{4}=17.5 \mathrm{~mm}, \quad l_{\mathrm{v}}=9 \mathrm{~mm}, \quad l_{\mathrm{h}}=27.4 \mathrm{~mm}, \quad l_{\mathrm{f}}=14 \mathrm{~mm}, \quad w_{\mathrm{f}}=$ $3.14 \mathrm{~mm}$, and $d=1 \mathrm{~mm}$, respectively. The diodes used as switching elements are BAR50-02V. According to the datasheet of the BAR50-02V, the diodes are modeled by a resistance of $3 \Omega$ for on state and a parallel circuit with a capacitance of $0.15 \mathrm{pF}$ and a resistance of $5 \mathrm{k} \Omega$ for off state. The operation modes of the antenna are shown in Table 1.

2.2. Frequency Reconfigurability. Frequency reconfigurability can be realized by simultaneously turning the switches $\mathrm{D}_{1}$ and $\mathrm{D}_{2}$ on or off. Figures 2 and 3 show the simulated input 


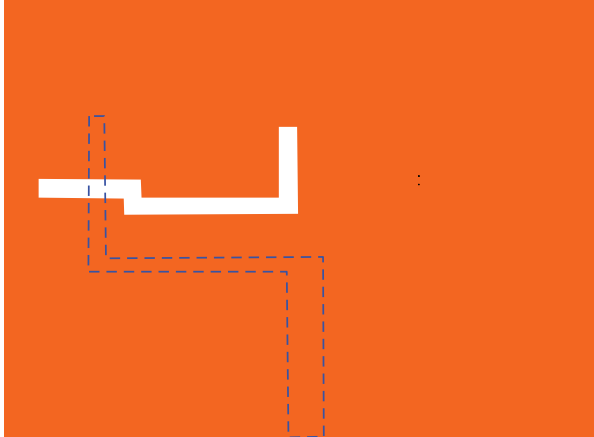

(a)

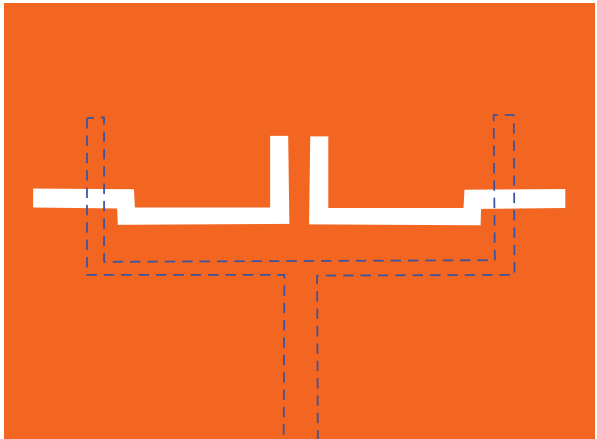

(b)

FIgURE 6: Slot antennas with asymmetric and symmetric structures. (a) Antenna 1. (b) Antenna 2.

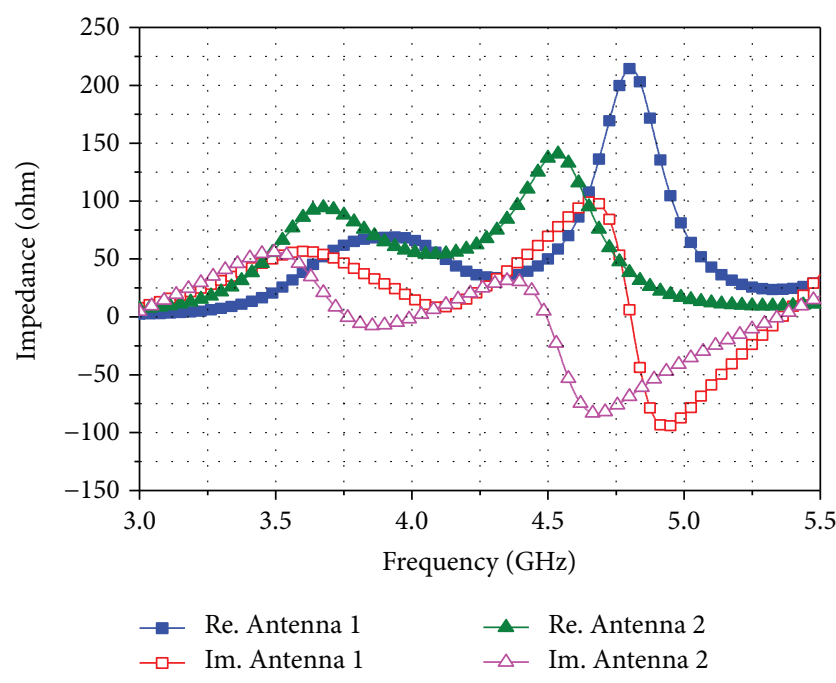

FIGURE 7: Input impedance of antennas in Figure 6.

reflection coefficients of the antenna. It is obvious that when $\mathrm{D}_{1}$ and $\mathrm{D}_{2}$ are turned off (modes 1,2 , and 3 ), the antenna operates in $3.38-3.88 \mathrm{GHz}$ band. Alternatively, when $\mathrm{D}_{1}$ and $\mathrm{D}_{2}$ are turned on (modes 4,5 , and 6), the antenna works in $3.69-4.2 \mathrm{GHz}$ band. The simulated bandwidths in the six modes are $17.4 \%(3.26-3.88 \mathrm{GHz}), 15.3 \%(3.38-3.94 \mathrm{GHz})$, $15.3 \% \quad(3.38-3.94 \mathrm{GHz}), \quad 16.2 \% \quad(3.69-4.34 \mathrm{GHz}), \quad 14.8 \%$ $(3.62-4.2 \mathrm{GHz})$, and $14.8 \%(3.62-4.2 \mathrm{GHz})$, respectively.

To illustrate the mechanism of frequency reconfiguration, the surface current distributions of the antenna are investigated. The simulated surface current distributions in modes 1, 2, and 3 are shown in Figure 4 . It can be seen that the current concentrates on the edge of the sickleshaped slots, and the corresponding current path length $\left(w_{1}+l_{1}+w_{2}+l_{2}\right)$ is approximately $\lambda_{1} / 2\left(\lambda_{1}\right.$ is the guided wavelength at $3.5 \mathrm{GHz}$ ). While in modes 4,5 , and 6 , as shown in Figure 5, the current mainly flows along the edge of the sickle-shaped slots, and the current path length $\left(w_{1}+l_{1}+w_{2}+l_{3}\right)$ is approximately $\lambda_{2} / 2\left(\lambda_{2}\right.$ is the guided wavelength at $3.8 \mathrm{GHz}$ ).

2.3. Pattern Reconfigurability. Pattern reconfigurability can be achieved by controlling the states of switches $D_{3}$ and $D_{4}$.

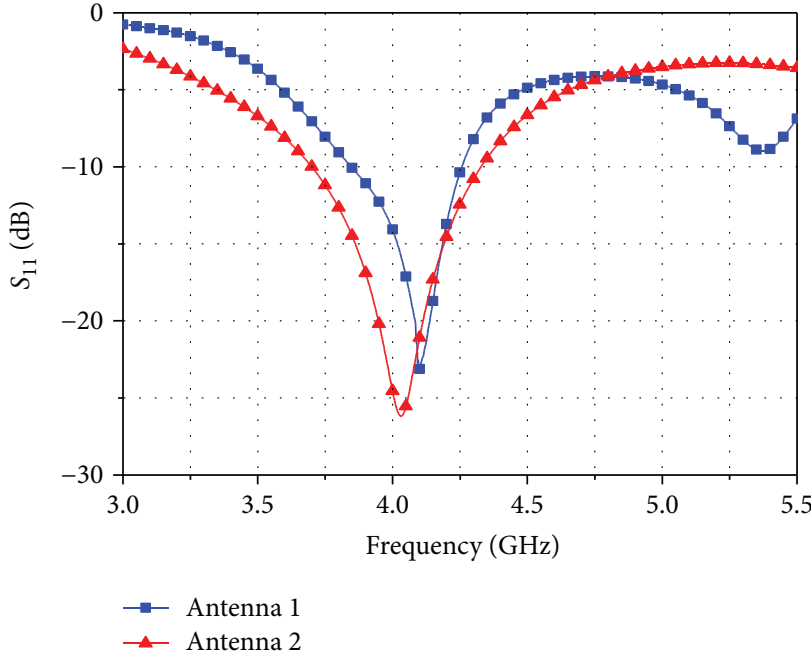

Figure 8: $\left|S_{11}\right|$ of antennas in Figure 6.

For the sake of brevity, we illustrate the patternreconfigurable mechanism in $3.4-3.8 \mathrm{GHz}$ band. As shown in Figure 4(a), it can be seen that when switches $D_{3}$ and $D_{4}$ are turned on, the current flows along the slots, and thus, the antenna exhibits almost omnidirectional radiation patterns. In Figure 5(b), when $\mathrm{D}_{3}$ is turned off and $\mathrm{D}_{4}$ is turned on, more signals and waves are concentrated on the right slot, and the left radiation power is mainly suppressed, which results in a main lobe directed at $+30^{\circ}$. Similarly, when $\mathrm{D}_{3}$ is turned on and $\mathrm{D}_{4}$ is turned off, as shown in Figure 5(c), more signals and waves are concentrated on the left slot and the right radiation power is mainly suppressed, which results in a main lobe directed at $-30^{\circ}$. The mechanism of pattern reconfigurability in $3.7-4.2 \mathrm{GHz}$ band is the same as that in $3.4-3.8 \mathrm{GHz}$ band. The simulated efficiencies in the six modes are approximately $80 \%$, $70 \%, 70 \%, 77 \%, 69 \%$, and $69 \%$, respectively. The lower efficiency in $3.4-3.8 \mathrm{GHz}$ band is mainly caused by more loss of the diodes.

Furthermore, in order to illustrate the wideband operation of the proposed antenna, two slot antennas with asymmetric and symmetric structures (antennas 1 and 2) are studied, as shown in Figure 6. Without loss of generality, 


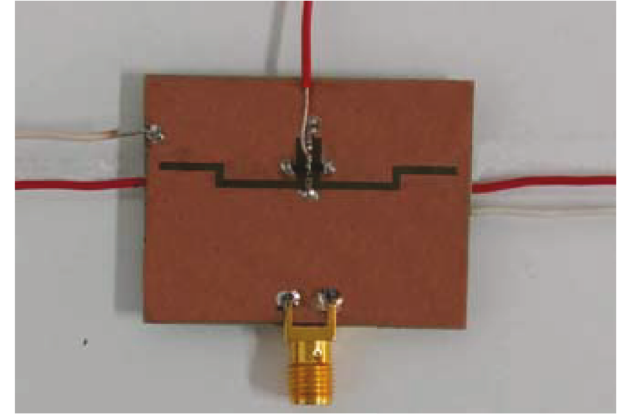

(a)

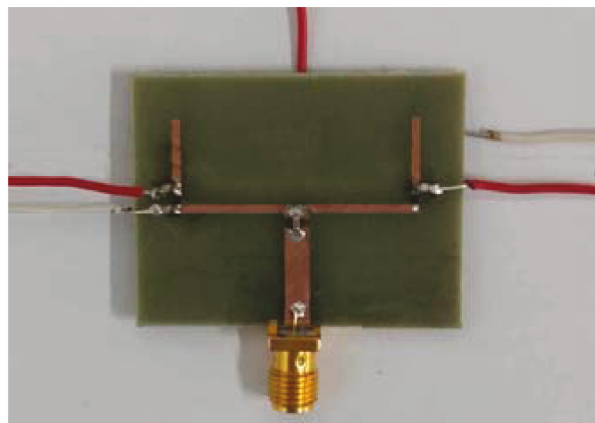

(b)

Figure 9: Photograph of the antenna. (a) Top view. (b) Bottom view.

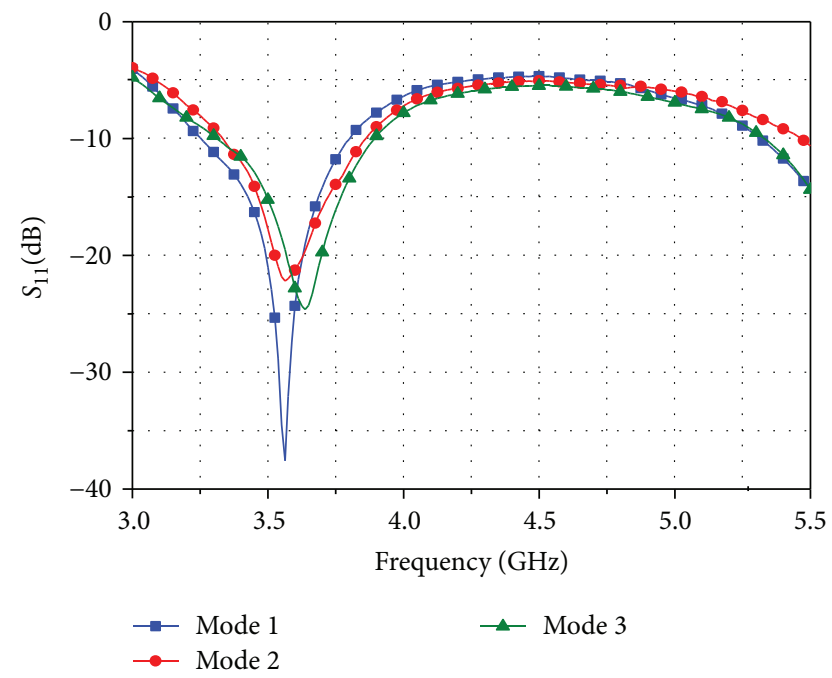

FIGURE 10: Measured input reflection coefficients in modes 1, 2, and 3 .

we investigated the slot antennas in mode 4 . The input impedance of antennas 1 and 2 is shown in Figure 7 . It can be observed that, when the input impedance is close to $50 \mathrm{ohm}$, the frequency range of antenna 1 is $400 \mathrm{MHz}$ $(3.85-4.25 \mathrm{GHz})$ and that of antenna 2 is $630 \mathrm{MHz}(3.7-$ $4.33 \mathrm{GHz})$. That is, better impedance matching of antenna 2 is obtained. Figure 8 shows the reflection coefficients of antennas 1 and 2 . It is noticed that antenna 2 has a wider bandwidth. Therefore, the introduction of the symmetric slots and fork-shaped feed line can improve the bandwidth of the proposed antenna. The principle of wideband operation of the antenna in other modes is the same as that in mode 4 . That is, better impedance matching of antenna 2 is obtained. Figure 8 shows the input reflection coefficients of antennas 1 and 2 .

\section{Experimental Results}

The antenna is fabricated on FR4 substrate with a thickness of $1.6 \mathrm{~mm}$, a relative permittivity of 4.4 , and a loss tangent of 0.02 . Figure 9 shows the photo of the antenna. The input reflection coefficients are measured by an Agilent N5230A vector network analyzer, and the radiation patterns and gains

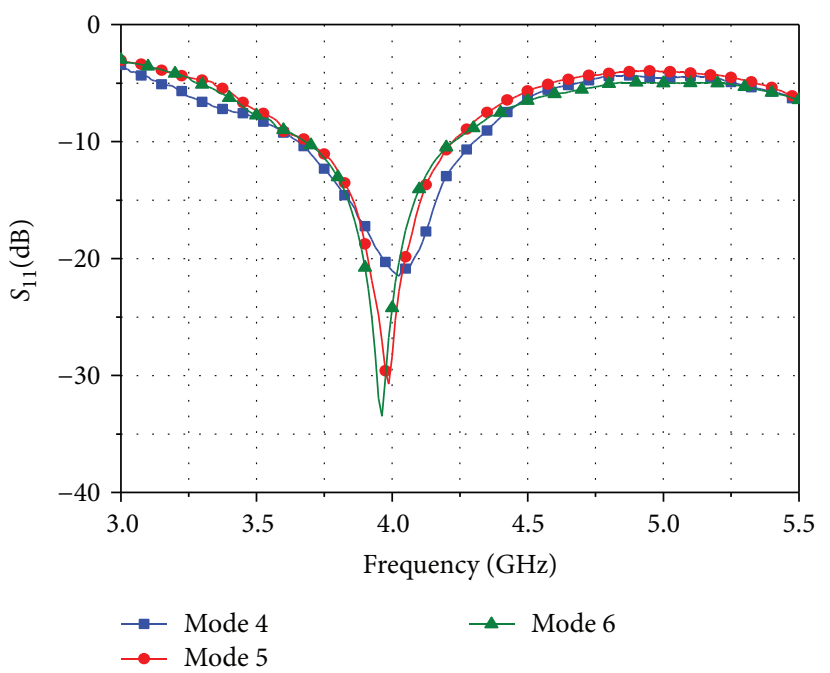

FIgURE 11: Measured input reflection coefficients in modes 4, 5, and 6 .

are measured by the Lab-Volt 8092 antenna training and measuring system in an anechoic chamber. A far-field antenna test range is used to measure the pattern. In the test range, the proposed antenna is mounted on a turntable and serves as the receiving antenna. A standard horn, at a distance of $1 \mathrm{~m}$ away, is used as the fixed transmitting antenna.

Figures 10 and 11 show the measured input reflection coefficients of the antenna. It is observed that the antenna operates from 3.38 to $3.88 \mathrm{GHz}$ in modes $1-3$ and from 3.69 to $4.2 \mathrm{GHz}$ in modes $4-6$. The bandwidths in the six modes are $14.9 \%(3.27-3.8 \mathrm{GHz}), 15.4 \%(3.38-3.93 \mathrm{GHz})$, $15.7 \% \quad(3.31-3.88 \mathrm{GHz}), \quad 15.9 \% \quad(3.66-4.3 \mathrm{GHz}), \quad 12.8 \%$ $(3.7-4.21 \mathrm{GHz})$, and $13.6 \%(3.68-4.22 \mathrm{GHz})$, respectively. Compared with the simulated results shown in Figure 2, good agreement is obtained between the simulated and measured ones. The differences between the simulated and measured results are mainly caused by the parasitic effects of diodes, dc bias, and accuracy of the dielectric constant of the material.

The measured radiation patterns in the $\mathrm{H}$-plane are plotted in Figure 12. It can be seen that the antenna has the capability to change its patterns in two bands, and the cross-polarization level is less than $-18 \mathrm{~dB}$ for six modes. 


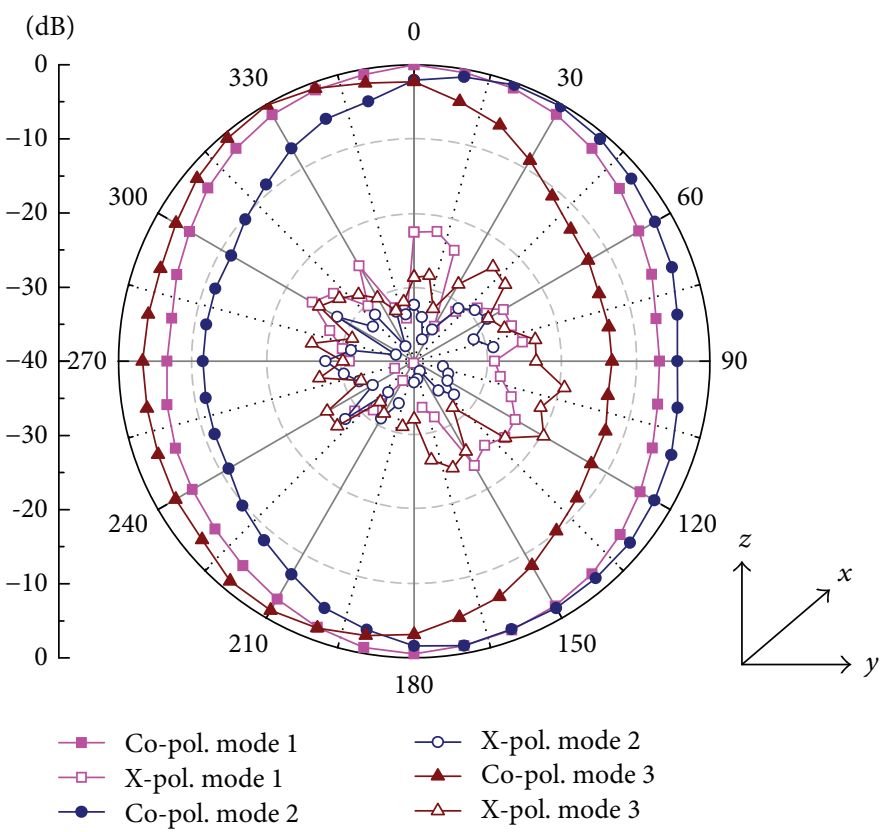

(a)

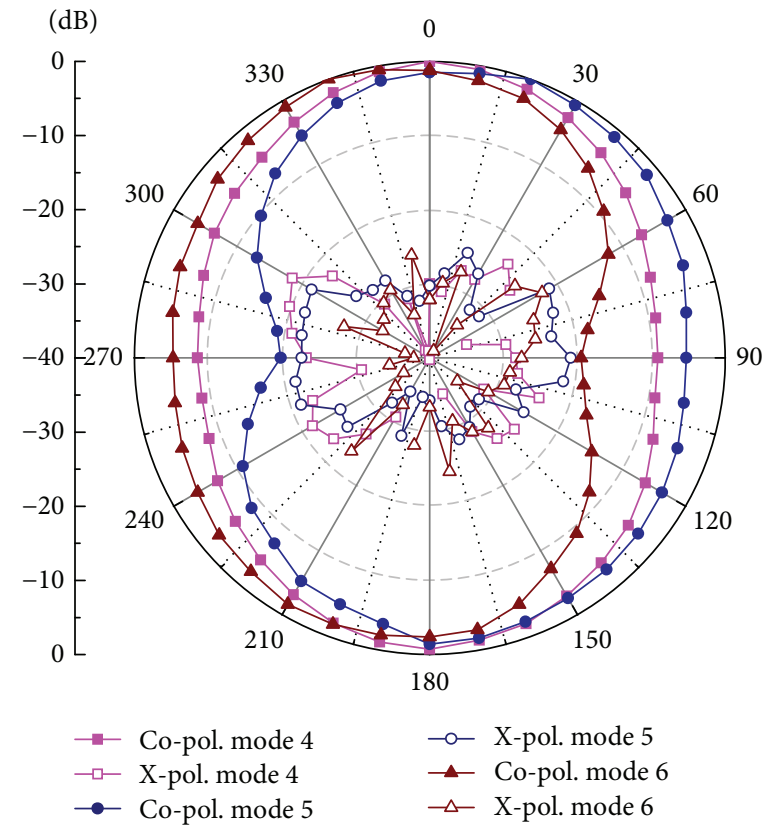

(b)

Figure 12: Measured radiation patterns in $y z$, H-plane. (a) Modes 1-3. (b) Modes 4-6.

TABle 2: Performance of frequency- and pattern-reconfigurable antennas.

\begin{tabular}{|c|c|c|c|c|c|c|}
\hline Antenna & Size $\left(\mathrm{mm}^{2}\right)$ & Switch number & Frequency number & Beam number & Min. FBW (\%) & Relative dimensions \\
\hline [11] & $34 \times 36$ & 2 & 2 & 2 & 2.3 & $0.62 \lambda_{1} \times 0.65 \lambda_{1}$ \\
\hline$[12]$ & $160 \times 130$ & 14 & 3 & 3 & 4.2 & $1.45 \lambda_{1} \times 1.18 \lambda_{1}$ \\
\hline [13] & $45.8 \times 80$ & 5 & 2 & 1 & 5.6 & $0.46 \lambda_{1} \times 0.8 \lambda_{1}$ \\
\hline$[14]$ & $120 \times 120$ & 12 & 2 & 3 & 2.5 & $\lambda_{1} \times \lambda_{1}$ \\
\hline [15] & $\pi \times 60 \times 60$ & 5 & 2 & 6 & 4.9 & $1.32 \lambda_{1} \times 1.32 \lambda_{1}$ \\
\hline Proposed & $40 \times 30$ & 4 & 2 & 3 & 12.8 & $0.71 \lambda_{1} \times 0.53 \lambda_{1}$ \\
\hline
\end{tabular}

The measurements show that the antenna exhibits $25^{\circ}$ and $20^{\circ}$ beam-steering in 3.4-3.8 and 3.7-4.2 GHz bands, respectively. The measured peak gains in the six modes are 2.24, $2.45,2.8,2.21,2.53$, and $2.76 \mathrm{dBi}$. Compared with the simulated results, the measurements decrease 0.7, 0.54, 0.19, $0.81,0.58$, and $0.35 \mathrm{~dB}$ due to the loss of diodes.

Finally, Table 2 lists the key data of this work and other reported frequency- and pattern-reconfigurable antennas. It is clear that the proposed antenna has the widest bandwidth and smallest size except reference [13]. Compared with the antenna having smaller size [13], the proposed antenna has fewer switches and more beams at the resonant frequency.

\section{Conclusion}

A wideband slot antenna with frequency and pattern reconfiguration is proposed. It covers the 3.4-3.8 and 3.74.2 $\mathrm{GHz}$ bands with three radiation patterns. Two PIN diodes are loaded in the sickle-shaped slots in the ground to produce two different frequency bands, and two additional PIN diodes are inserted in the fork-shaped feed line to achieve pattern reconfigurability. Simulated and measured results show that the antenna has the capability to change its patterns in TD-LTE $(3.4-3.8 \mathrm{GHz})$ and C-band $(3.7-4.2 \mathrm{GHz})$ with a compact size, which can be used in various multifrequency systems.

\section{Conflicts of Interest}

The authors declare that there is no conflict of interests regarding the publication of this article.

\section{Acknowledgments}

This work was supported by the National Science Foundation of China (61771295, 61172045), the Natural Science Foundation of Shanxi Province (2012011013-3, 2015011051), and the Fund for Shanxi “1331 Project” Key Subjects Construction.

\section{References}

[1] I. F. Akyildiz, W.-Y. Lee, M. C. Vuran, and S. Mohanty, "Next generation/dynamic spectrum access/cognitive radio wireless 
networks: a survey," Computer Networks, vol. 50, no. 13, pp. 2127-2159, 2006.

[2] R. Mehmood and J. W. Wallace, "Interference suppression using parasitic reconfigurable aperture (RECAP) antennas," in 2011 International Workshop on Antenna Technology (iWAT), pp. 82-85, Hong Kong, China, 2011.

[3] H. Eslami, C. P. Sukumar, D. Rodrigo et al., "Reduced overhead training for multi reconfigurable antennas with beam-tilting capability," IEEE Transactions on Wireless Communications, vol. 9, no. 12, pp. 3810-3821, 2010.

[4] M. Borhani, P. Rezaei, and A. Valuate, "Design of a reconfigurable miniaturized microstrip antenna for switchable multiband systems," IEEE Antennas and Wireless Propagation Letters, vol. 15, pp. 822-825, 2016.

[5] S. W. Lee and Y. Sung, "Compact frequency reconfigurable antenna for LTE/WWAN mobile handset applications," IEEE Transactions on Antennas and Propagation, vol. 63, no. 10, pp. 4572-4577, 2015.

[6] L. Han, C. Wang, X. Chen, and W. Zhang, "Compact frequency-reconfigurable slot antenna for wireless applications," IEEE Antennas and Wireless Propagation Letters, vol. 15, pp. 1795-1798, 2016.

[7] A. Khidre, F. Yang, and A. Z. Elsherbeni, "A patch antenna with a varactor-loaded slot for reconfigurable dual-band operation," IEEE Transactions on Antennas and Propagation, vol. 63, no. 2, pp. 755-760, 2015.

[8] S. Xiao, C. Zheng, M. Li, J. Xiong, and B.-Z. Wang, "Varactorloaded pattern reconfigurable array for wide-angle scanning with low gain fluctuation," IEEE Transactions on Antennas and Propagation, vol. 63, no. 5, pp. 2364-2369, 2015.

[9] T. Aboufoul, C. Parini, X. Chen, and A. Alomainy, "Patternreconfigurable planar circular ultra-wideband monopole antenna," IEEE Transactions on Antennas and Propagation, vol. 61, no. 10, pp. 4973-4980, 2013.

[10] Z. Li, E. Ahmed, A. M. Eltawil, and B. A. Cetiner, "A beamsteering reconfigurable antenna for WLAN applications," IEEE Transactions on Antennas and Propagation, vol. 63, no. 1, pp. 24-32, 2015.

[11] G. H. Huff, J. Feng, S. Zhang, and J. T. Bernhard, "A novel radiation pattern and frequency reconfigurable single turn square spiral microstrip antenna," IEEE Microwave and Wireless Components Letters, vol. 13, no. 2, pp. 57-59, 2003.

[12] H. A. Majid, M. K. A. Rahim, M. R. Hamid, and M. F. Ismail, "Frequency and pattern reconfigurable slot antenna," IEEE Transactions on Antennas and Propagation, vol. 62, no. 10, pp. 5339-5343, 2014.

[13] P. K. Li, Z. H. Shao, Q. Wang, and Y. J. Cheng, "Frequencyand pattern-reconfigurable antenna for multistandard wireless applications," IEEE Antennas and Wireless Propagation Letters, vol. 14, pp. 333-336, 2015.

[14] N. Ramli, M. T. Ali, M. T. Islam, A. L. Yusof, and S. Muhamud-Kayat, "Aperture-coupled frequency and patterns reconfigurable microstrip stacked array antenna," IEEE Transactions on Antennas and Propagation, vol. 63, no. 3, pp. 1067-1074, 2015.

[15] T. Guo, W. Leng, A. Wang, J. Li, and Q. Zhang, “A novel planar parasitic array antenna with frequency- and patternreconfigurable characteristics," IEEE Antennas and Wireless Propagation Letters, vol. 13, pp. 1569-1572, 2014. 


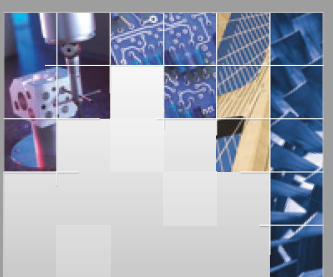

\section{Enfincering}
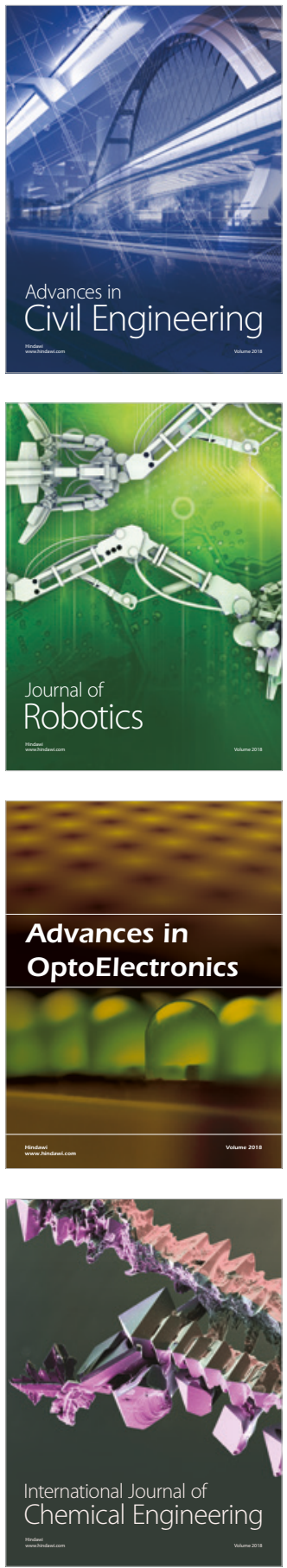

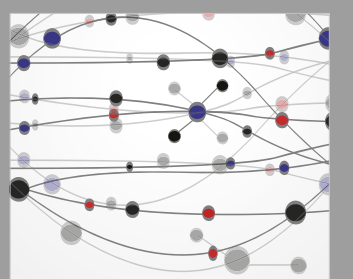

\section{Rotating \\ Machinery}

The Scientific World Journal

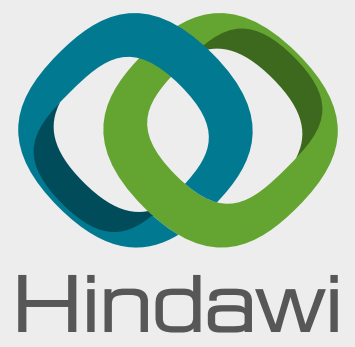

Submit your manuscripts at

www.hindawi.com
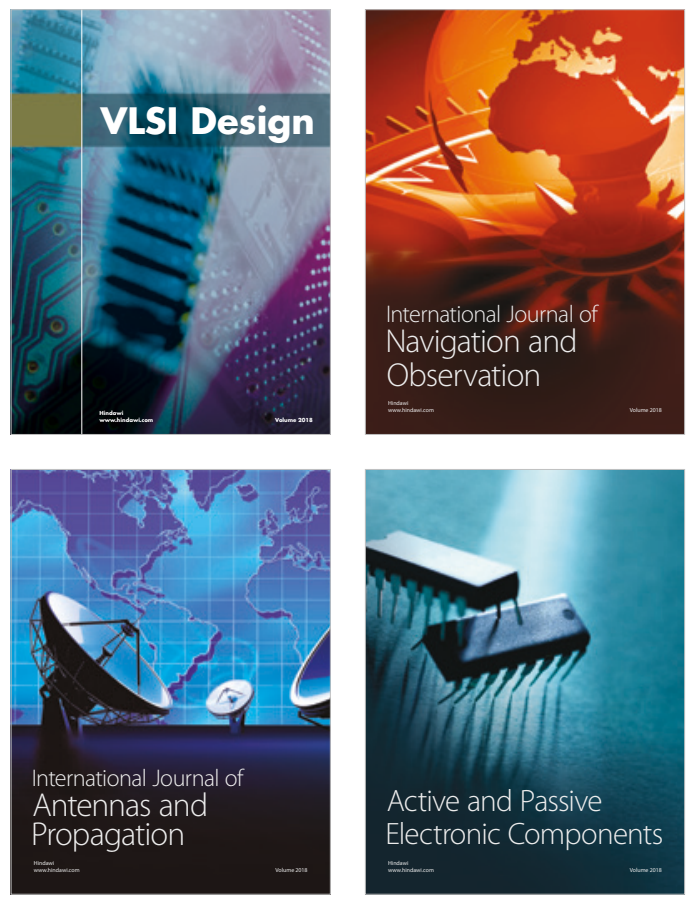
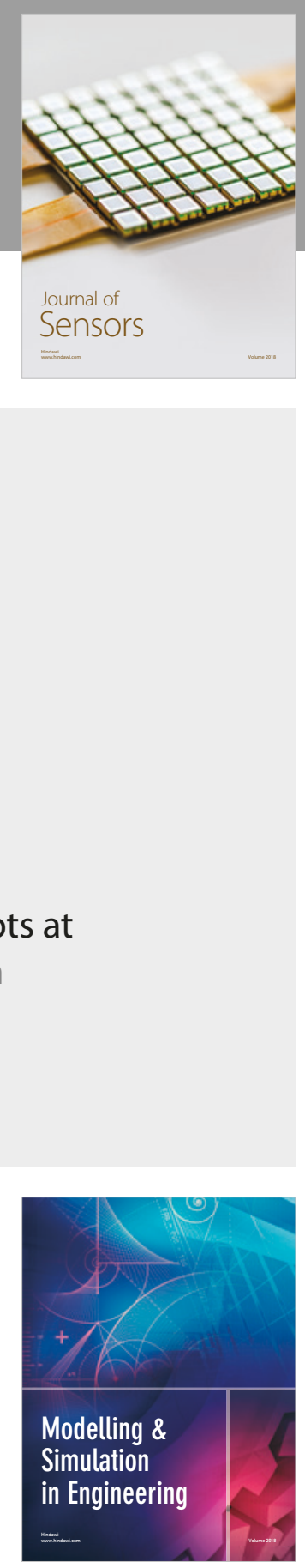

\section{Advances \\ Multimedia}
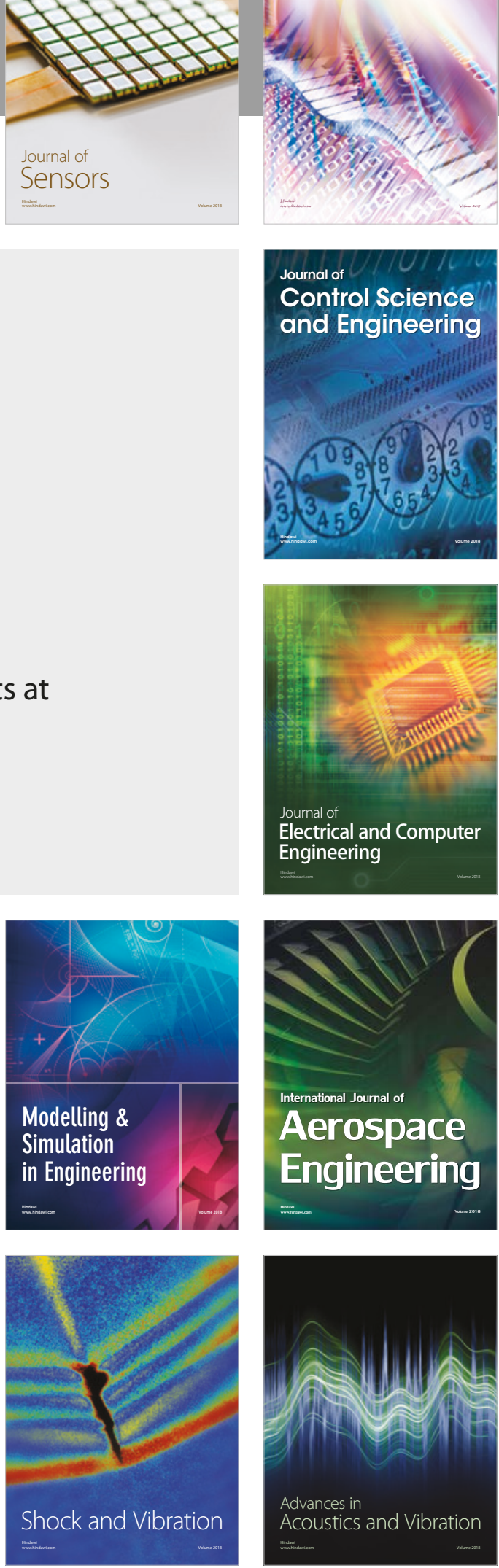